\title{
Protein S deficiency: early presentation and pulmonary hypertension
}

\author{
J O’Sullivan, R Chatuverdi, M K Bennett, S Hunter
}

\begin{abstract}
Protein S deficiency usually presents in adults with recurrent or unexplained thrombosis and is thought to have autosomal dominant inheritance. We describe the case of a 5 year old girl with pulmonary hypertension but no evidence of venous thrombosis until postmortem examination. Her parents were first cousins. This potentially treatable condition should be sought in children and their relatives screened.
\end{abstract}

Protein $S$ is a vitamin $\mathrm{K}$ dependent plasma protein which inhibits blood clotting by acting as a cofactor for protein $\mathrm{C}$ which in turn inhibits the clotting cascade at the levels of factor $V$ and factor VIII. Protein S exists in two forms in the plasma: free (active) or bound to plasma protein (inactive). It is very rare for symptoms to occur in childhood. We report the case of a 5 year old girl who was referred for assessment of pulmonary hypertension and the diagnosis of protein $S$ deficiency became apparent after she died suddenly.

\section{Case history}

A 5 year old girl presented to her local hospital with a five week history of breathlessness, general lassitude, and cyanosis. Her parents were first cousins and there was no family history of cardiopulmonary problems. At 1 month of age she had had a patent arterial duct ligated. She had made an uneventful recovery from this and had been discharged from the cardiology clinic at the age of 6 months.

On admission at the age of 5 years she was centrally cyanosed, with oxygen saturations of about $75 \%$ in room air; she showed only slight improvement on $100 \%$ oxygen. She had clinical evidence of pulmonary hypertension with no obvious murmurs. A chest radiograph showed cardiomegaly and the electrocardiogram demonstrated right ventricular hypertrophy. Cross sectional echocardiography demonstrated gross right atrial and right ventr: :ular enlargement and marked tricuspid regurgitation. There was moderate global impairment of left ventricular function and a mass in the ventricular apex which was thought to represent a clot, but the differential diagnosis at that stage included a tumour. Ultrasound of the abdomen was normal.

She was anticoagulated and received $3 \mathrm{mg}$ of warfarin on two consecutive days and then heparinised (10 000 units/day). A ventilation perfusion scan was highly suggestive of chronic pulmonary embolism with multiple perfusion defects bilaterally. Cardiac catheterisation was preceded by an inferior venacavogram which showed noobvious clot. Pulmonary hypertension was confirmed (total pulmonary vascular resistance $=26.6 \mathrm{units} / \mathrm{m}^{2}$ ) at the cardiac catheter and there was no significant response to $100 \%$ oxygen. A pulmonary angiogram confirmed perfusion defects in the lung with small distal vessels. Even though the evidence was somewhat conflicting, it was felt in the absence of evidence of peripheral venous thrombosis the most likely diagnosis was primary pulmonary hypertension. However, in view of the possible thrombus in the left ventricle she was maintained on heparin. She was considered for heart-lung transplantation but on her 15th day in hospital she had a cardiac arrest from which she could not be resuscitated.

At necropsy, antemortem thrombus was found in the left and right ventricles and inferior vena cava. There was no active inflammatory infiltrate or evidence of structural abnormality in the inferior vena cava. The pulmonary artery was atheromatous. Patchy areas of infarction were found in the lower lobes of both lungs and the right middle lobe. There was no recent infarction. Histological examination of the lungs showed extensive fibrin thrombus within the pulmonary arteries associated with infarction of distal tissue in all lobes of the lung. There was no histological evidence of vasculiltis affecting the lung.

Haematological results from antemortem blood were only then available and were (range): protein C (immunological) $60 \%$ (55-123), antithrombin III $73 \%(80-120)$, and protein $S$ (total) 6\% (60-120). The protein $S$ concentration was measured eight days after the second dose of warfarin and the international normalised ratio was 1 . An enzyme immunoassay (asserachromproteine S, Diagnostica Stago) was used to measure protein $\mathrm{S}$. Her immediate family were screened and the protein $S$ concentrations were normal. There was no family history on detailed retrospective questioning of venous or arterial thrombosis.

\section{Discussion}

Protein $S$ is a vitamin $K$ dependent natural anticoagulant that acts as a cofactor for protein $\mathrm{C}$ in inactivating the procoagulants factor $\mathrm{V}$ and factor VIII. Protein S'deficiency was linked to thrombus formation in $1984 .^{1}$ Two types of deficiency are described. In type I there is little free protein $S$, although there is a significant amount bound to plasma protein. Type II is characterised by reduction of both the bound 
and free forms. It is usually described as an autosomal dominant condition and the gene has been assigned to chromosome 3 . There is evidence to suggest that two genes for protein $S$ are present within the human genome. ${ }^{2} \mathrm{~A}$ Japanese paper reported several cases of severe protein $S$ deficiency in consanguinous members of a large pedigree. ${ }^{3}$ In our patient the parents were first cousins. These reports may suggest autosomal recessive inheritance and the genetics of the disorder require clarification.

The profoundly low protein $S$ concentration cannot be attributed to warfarin. The blood sample was taken eight days after the last dose of warfarin and it is known that warfarin tends to depress protein $\mathrm{C}$ concentrations more than protein $S,{ }^{4}$ the reverse occurring in our case.

Individuals with low protein $S$ concentrations may not develop thrombosis and therefore other, as yet undefined, factors are important in the clinical significance of deficiency. There are few reports in the literature of thrombosis presenting at less than 15 years of age $\mathrm{e}^{4-7}$ and to the best of our knowledge this is the first case where the child died from the thrombosis. We cannot explain why this girl presented so young with such severe pulmonary hypertension as the absolute concentration does not appear to correspond to clinical severity. ${ }^{4}$

A feature of protein $S$ deficiency is the tendency to arterial thrombosis. ${ }^{47}$ The patient under discussion had a clot evident in the left ventricle and we would now suggest that a patient of whatever age with unexplained pulmonary hypertension and evidence of arterial thrombus should be considered as having protein $S$ deficiency until proved otherwise. This case highlights the fact that protein $S$ deficiency may present and be lethal in young children. The diagnosis has treatment and possible genetic implications and it is therefore important that it should not be missed. Protein S concentrations should be checked routinely in children and adults presenting with unexplained thrombosis and in patients diagnosed as having primary pulmonary hypertension, as thrombosis may not be obvious clinically. One should be particularly vigilant if there is associated arterial thrombosis.

1 Comp PC, Esmon CT. Recurrent venous thromboembolism in patients with a partial deficiency of protein $\mathrm{S}$. $N$ Engl f Med 1984;311:1525-8.

2 Ploos van Amstel J, Van der Zanden A, Reitsma P, Bertina $R$. Two genes homologous with human protein $S$ cDNA are located on chromosome 3. Thromb Haemost 1987;58:982-7.

3 Kamiya T, Sugihara T, Ogata K, et al. Inherited deficiency of protein $S$ in a Japanese family with recurrent venous
thrombosis: a study of three generations. Blood 1986;67: 406-10.

4 Dolan G, Ball J, Preston FE. Protein $C$ and protein S. Ballière's clinical haematology. Vol 2. London: Ballière
Tindall, 1989:999-1042. 5 Tindall, 1989 : 9904

5 Mannucci PM, Tripodi A, Bertina RM. Protein S deficiency associated with 'juvenile' arterial and venous thrombosis. Thromb Haemost 1986;55:440 (letter)

6 Sas Y, Blasko Y, Petro I, Griffin JH. A protein S deficient family with portal vein thrombosis. Thromb Haemost 1985; 54:724.

7 Sie $\mathrm{P}$, Boneu B, Bierme R, et al. Arterial thrombosis and protein S deficiency. Thromb Haemost 1989;62:1040. 